\title{
DLC Coatings in Oil and Gas Production
}

\author{
Tomasz Liskiewicz and Amal Al-Borno
}

\author{
Charter Coating Service (2000) Ltd. No. 6, 4604 13th Street NE, Calgary, AB, T2E 6P1, Canada
}

\begin{abstract}
Diamond-like carbon (DLC) coatings are recognized in many sectors as a promising way of controlling wear and the corrosion performance of components. DLC coatings are well established in the automotive industry where they are applied to the moving parts of direct injection fuel systems operating under frictional conditions at high pressures and in the aggressive environment of the combustion chamber. Over the last few years, there have also been an increasing number of reports of DLC coating applications in oil and gas production contexts, including in pipes, shut-off gates and various types of valves.

This paper reviews current efforts to use DLC coatings in the oil and gas sectors and analyses typical coating degradation mechanisms including wear and wear-accelerated corrosion regimes. DLC coating deposition techniques including Physical (PVD) and Chemical Vapor Deposition (CVD) techniques are elaborated and the unique coating properties obtained from those two methods are assessed. Surface functionalization is discussed including dopants ( $\mathrm{W}$ and $\mathrm{Si}$ ) and gradient interlayers. Finally, the outlook for future use of DLC coatings in oil and gas production is discussed.
\end{abstract}

Received on 03-03-2014 Accepted on 28-05-2014 Published on 25-06-2014

Keywords: Diamond-like carbon, DLC, surface engineering, functional coatings, tribology, corrosion.

\section{INTRODUCTION}

Amongst the wide range of coatings achieved by surface engineering processes, diamond-like carbon (DLC) thin films are recognized across different sectors as a promising way of controlling surface properties of various components. Surface engineering itself is a design process, involving the surface and substrate together as a functionally graded system to give a cost-effective performance enhancement of which neither is capable on its own [1]. This is a critical technology, underpinning major industry sectors including aerospace, automotive, oil and gas, construction, power generation and bio-medical applications [2]. Appropriate coating can solve a diverse array of engineering problems and provide protection against corrosion, wear damage or high temperature. Moreover, surface engineering solutions can also supply added-value, increasing economic and environmental benefits.

Operating environments in oil and gas exploration and the transportation industry are severe in terms of temperatures and in terms of the presence of abrasive and corrosive media. Hence, surface engineering technologies for oil and gas applications are designed to provide thick and robust, wear and corrosion resistant coatings. Established coating processes include thermal sprayed coatings [3], diffusion

"Charter Coating Service (2000) Ltd. No. 6, 4604 13th Street NE, Calgary, AB, T2E 6P1, Canada; Tel: 001-403-250-3027; Fax: 001-403-250-1254;

E-mail: tliskiewicz@chartercoating.com coatings [4], electro-deposition [5] and overlays produced by hardfacing [6]. While these technologies have been established over years, currently demand for new and more sophisticated functional thin film coatings is observed, driven by new requirements and higher efficiency and safety standards for emerging applications.

The term 'thin film technologies' is related to coatings achieved by Physical Vapour Deposition (PVD) and Chemical Vapour Deposition (CVD) processes. PVD coating is produced by the condensation of a vaporized form of the material onto various surfaces [7], while CVD involves chemical volatile precursors, which react with the substrate surface to produce the desired deposit [8]. Both methods allow thin films, typically less than $10 \mu \mathrm{m}$ thick, to be obtained, which are characterized by superior mechanical properties. It is a truly remarkable fact that a coating that is ten times thinner than a human hair can extend the lifetime of a certain mechanical component by over a hundred-fold, as is the case in cutting tools technology [9].

PVD methods offer a wide range of metallic and ceramic coatings with superior aesthetics and excellent tribological/corrosive performance. PVD methods have been established as successful and highly efficient industrial technologies providing high quality coatings through environmentally friendly and repeatable processes. To achieve an optimum coating durability and performance, PVD thin films are usually deposited on metallic substrates which 
can provide good mechanical support and optimum adhesion at the coating/substrate interface.

The evolution of surface engineering and thin films technologies is underpinned by increasing application requirements for engineering products: higher precision, longer lifetime, higher power densities and lower production and maintenance costs. Therefore, it is expected that demand for thin film coatings will also rise steadily. Among those, DLC coatings will play a significant role.

\section{TYPES OF DLC COATINGS}

DLC is a generic term used to describe a range of amorphous carbon films which include hydrogen free DLC (aC), hydrogenated DLC (a-C:H), tetrahedral amorphous carbon (ta-C), hydrogenated tetrahedral amorphous carbon (ta-C:H), and those containing silicon or metal dopants, such as Si DLC and Me DLC. The first report of successful deposition of DLC coating dates back to 1971, when Aisenberg and Chabot processed hydrogen free diamond-like carbon films using carbon ions [10]. Since then, DLC coatings have attracted a lot of attention and found many practical applications across industrial sectors, including razor blades, computer hard drives, silicon solar cells, MEMS applications, orthopedic implants, optical lenses, and finally cutting tools and internal combustion engine components.

Diamond and graphite are the most well-known allotropes of carbon. Diamond is the hardest known natural mineral, which makes it an excellent abrasive, while graphite is soft and slippery and in its powder form is used as a dry lubricant. These extremely diverse properties result from the different types of bonding between carbon atoms, including $\mathrm{sp}^{3}, \mathrm{sp}^{2}$ and $\mathrm{sp}^{1}$ hybridizations [11]. Diamond has an $\mathrm{sp}^{3}$ hybridized bonds configuration resulting in strong $\mathrm{C}-\mathrm{C}$ bonds, while graphite has a three-fold coordinated $\mathrm{sp}^{2}$ hybridized bonds configuration forming weak bonding between the atomic planes. Diamond-like carbon is a metastable form of amorphous carbon and has a mixture of $\mathrm{sp}^{3}$ and $\mathrm{sp}^{2}$ bonding. Depending on hydrogen content and ratio of $\mathrm{sp}^{3} / \mathrm{sp}^{2}$ bonds, DLC coatings are divided in different groups, as shown in Figure 1.

The ratio of $\mathrm{sp}^{3} / \mathrm{sp}^{2}$ bonds and the hydrogen content in the coating determine the properties of DLC films. Some coating deposition techniques use hydrocarbon gases as a source of carbon and thus DLC coatings contain always a certain amount of hydrogen. The hydrogen content affects the structure of DLC coatings and it can vary from less than $1 \%$ in non-hydrogenated DLC films to about $60 \%$ in hydrogenated DLC films. Amorphous, non-hydrogenated carbon ( $\mathrm{a}-\mathrm{C})$ coatings are dominated by $\mathrm{sp}^{2}$ bonds and have typically less than $1 \%$ of hydrogen. The types of materials belonging to that group include soot, chars, glassy carbon and evaporated a-C. Hydrogenated amorphous carbon (a$\mathrm{C}: \mathrm{H})$ films have varying amounts of $\mathrm{sp}^{3}, \mathrm{sp}^{2}$ bonds and hydrogen content, resulting in a wide range of properties of these coatings. These properties are directly correlated to the fraction of $\mathrm{sp}^{3}$ bonds in the films.

Tetrahedral amorphous carbon (ta-C) coatings have the highest fraction of $\mathrm{sp}^{3}$ hybridized bonds, which can vary between 50 and $90 \%$ depending on the fabrication conditions. Ta-C coatings are synthesized typically from solid graphite and as a result do not contain a significant amount of hydrogen. The properties of the film vary depending on the $\mathrm{sp}^{2}$ clusters in the film but with the $\mathrm{sp}^{3}$ hybridized bonds content, at the high end of the ternary phase diagram, ta- $\mathrm{C}$ coatings have the closest of the DLC coatings to the properties of crystalline diamond. Hydrogenated tetrahedral amorphous carbon (ta- $\mathrm{C}: \mathrm{H}$ ) coatings have typically around $30 \%$ hydrogen content and variable fraction of $\mathrm{sp}^{3} / \mathrm{sp}^{2}$ hybridized bonds, similar to that observed in ta-C films. Nonhydrogenated ta-C films with low $\mathrm{sp}^{2}$ content are characterized by a very rigid network, while hydrogenated ta-

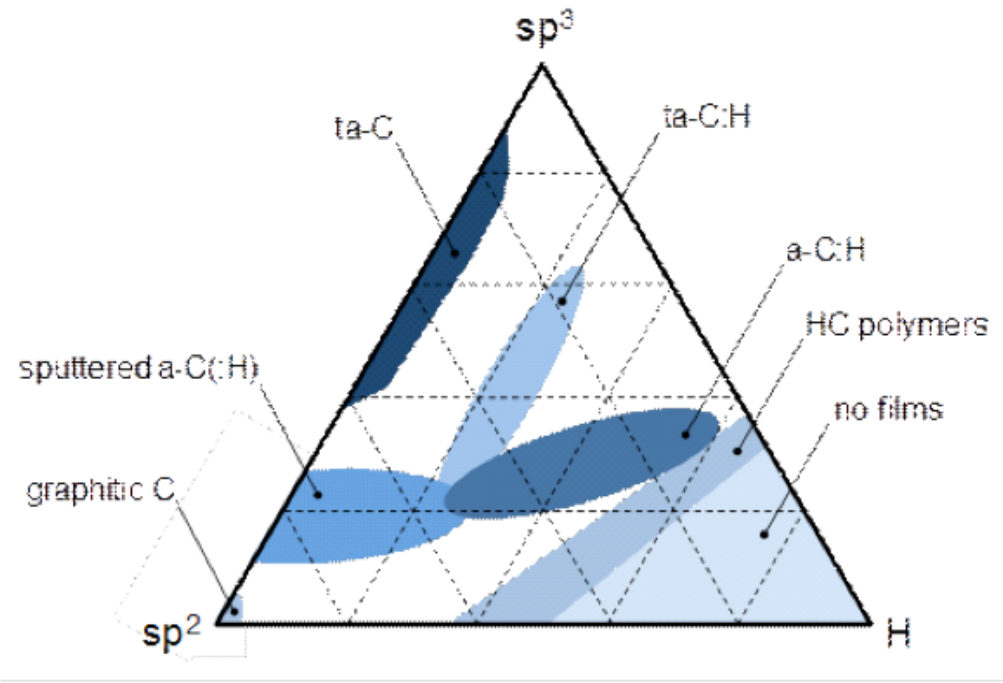

Figure 1: Ternary phase diagram of DLC films [after 12]. 
Table 1: Properties of Various Types of Carbon [after 13]

\begin{tabular}{|c|c|c|c|c|}
\hline & $\begin{array}{l}\mathrm{sp}^{3} \\
(\%)\end{array}$ & $\begin{array}{c}\mathrm{H} \\
(\%)\end{array}$ & $\begin{array}{l}\text { Density } \\
\left(\mathrm{g} \mathrm{cm}^{-3}\right)\end{array}$ & $\begin{array}{l}\text { Hardness } \\
\text { (GPa) }\end{array}$ \\
\hline Diamond & 100 & 0 & 3.5 & 100 \\
\hline Graphite & 0 & 0 & 2.3 & \\
\hline Glassy C & 0 & 0 & $1.3-1.5$ & 3 \\
\hline Evaporated C & 0 & 0 & 1.9 & 3 \\
\hline Sputtered C & 5 & 0 & 2.2 & \\
\hline ta-C & $80-88$ & 0 & 3.1 & 80 \\
\hline ta-C:H & 70 & 30 & 2.4 & 50 \\
\hline $\mathrm{a}-\mathrm{C}: \mathrm{H}$ hard & 40 & $30-40$ & $1.6-2.2$ & $10-20$ \\
\hline $\mathrm{a}-\mathrm{C}: \mathrm{H}$ soft & 60 & $40-50$ & $1.2-1.6$ & $<10$ \\
\hline
\end{tabular}

C films have a much softer polymeric network. Mechanical properties of DLC coatings are compared with their $\mathrm{sp}^{3}$ ratio and hydrogen content in Table 1.

With such a wide range of structural and mechanical properties, DLC coatings can be tailored to various applications where high hardness, low friction, good wear and corrosion resistance and chemical inertness are required properties. Hard tetrahedral amorphous carbon coatings are also characterized by a high Elastic Modulus, which is typically 6-10 times higher than their hardness [14]. This leads to high internal compressive stresses within the coating, limits its thickness and is a challenge in terms of adhesion to the coating/substrate interface. This problem is typically overcome by designing multi-layered coating architectures composed of a top DLC coating and adhesive interlayers, e.g., $\mathrm{Ti}$ or $\mathrm{Cr}$ (Figure 2). Properties of DLC coatings can be further modified by the addition of dopants, i.e., elements such as nitrogen, silicon, oxygen, fluorine or metals (Ti, Nb, Ta, Cr, Mo, W, Ru, Fe, Co, Ni, Al, Cu and Ag). Such modifications are made mainly to lower internal stress within the coating and improve adhesion but also to functionalize coating by lowering friction coefficient, reduce surface energy or modify electrical properties [15-17].

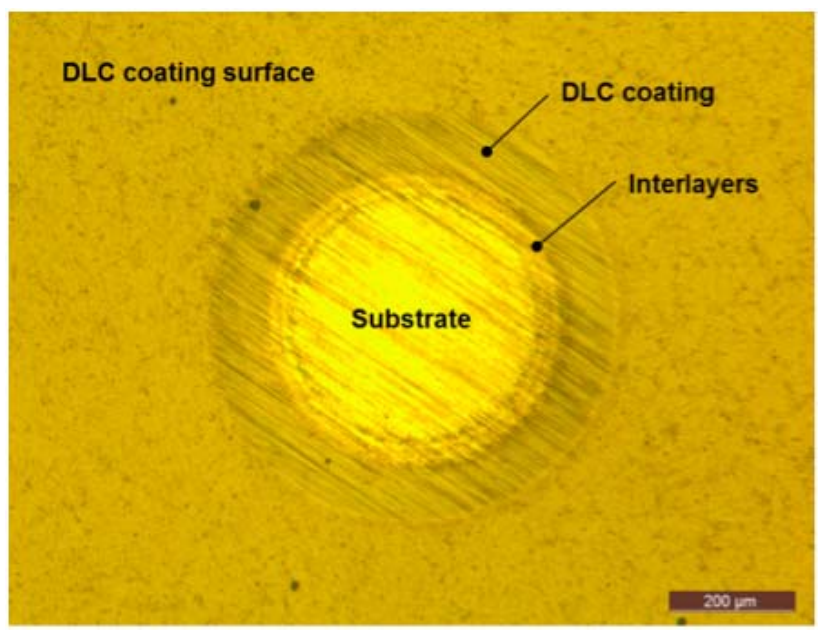

Figure 2: Optical microscope image of a ball crater worn through the DLC coating exposing the adhesive interlayers and the substrate.

\section{DEPOSITION TECHNIQUES}

DLC coatings are metastable materials and deposition methods of DLC films are non-equilibrium processes where energetic ions interact with the surface. Such films are deposited by Chemical Vapor Deposition (CVD) and Physical Vapor Deposition (PVD) techniques.

\section{Chemical Vapor Deposition}

Chemical vapor deposition is a technique where gaseous reactants can be deposited onto a substrate. Chemical reactions employed in the CVD coating deposition process are endothermic reactions and additional energy is required for initiation. In conventional CVD processes developed by Arkel and Boer [18], thermal energy is employed for necessary activation. The required temperature is typically in the range of $800^{\circ} \mathrm{C}-1100^{\circ} \mathrm{C}$, which often leads to dimensional distortion of metallic components and the necessity of an additional heat treatment operation after CVD deposition. One of the ways to decrease CVD process temperature is to replace the thermal energy component with another source of energy. This has been achieved in Plasma-Enhanced Chemical Vapor Deposition (PECVD) process, where electrical energy is used to generate a glow discharge (plasma) in which the energy is transferred into a gas mixture, allowing for a decrease in the deposition process temperature to $300-350^{\circ} \mathrm{C}$. Employment of plasma allows the transformation of the gas mixture into reactive radicals (ions, neutral atoms, molecules and other highly excited species) by collision in the gas phase, which allows the maintenance of a low temperature of the substrate material. DLC coatings deposited by means of PECVD method are typically processed in a chamber where acetylene $\left(\mathrm{C}_{2} \mathrm{H}_{2}\right)$ is cracked in the plasma and carbon molecules become available for coating growth on the substrate.

\section{Physical Vapor Deposition}

According to Bunshah [19], all coatings deposition techniques under reduced pressure in which thermal evaporation, sublimation and spraying phenomena are employed, can be 
Table 2: PECVD and PVD Types of DLC Coatings [after 22]

\begin{tabular}{|c|c|c|c|c|c|}
\hline & Metal-doped DLC & $\begin{array}{c}\text { Amorphous } \\
\text { hydrogenated DLC }\end{array}$ & Silicon-doped DLC & $\begin{array}{l}\text { Sputtered } \\
\text { DLC }\end{array}$ & $\begin{array}{l}\text { Hydrogen-free } \\
\text { DLC }\end{array}$ \\
\hline Type & WC-C:H & $\mathrm{a}-\mathrm{C}: \mathrm{H}$ & $\mathrm{a}-\mathrm{C}: \mathrm{H}-\mathrm{Si}$ & $\mathrm{a}-\mathrm{C}$ & ta-C \\
\hline Method & PVD/PECVD & PECVD & PECVD & PVD & PVD \\
\hline Hardness $\left(\mathrm{HV}_{0.05}\right)$ & $800-2200$ & $1500-3500$ & $1500-2500$ & $2000-4000$ & $3000-7000$ \\
\hline Coefficient of friction & $0.1-0.2$ & $0.05-0.15$ & $0.05-0.1$ & $0.05-0.1$ & $0.02-0.1$ \\
\hline Internal stress $(\mathrm{GPa} / \mu \mathrm{m})$ & $0.1-1.5$ & $1-3$ & $1-3$ & $2-6$ & $1-3$ \\
\hline Thickness $(\mu \mathrm{m})$ & $1-10$ & $1-10$ & $1-10$ & $1-3$ & $1-3$ \\
\hline Industrial use & yes & yes & yes & yes & yes \\
\hline Mass production & +++ & +++ & ++ & +++ & ++ \\
\hline
\end{tabular}

classified as PVD methods. Currently, dozens of variations and modifications of PVD techniques are available [20], all of them however have the following two attributes in common: (i) they are based on physical processes taking place under reduced pressure in the range of $10-10^{5} \mathrm{~Pa}$; (ii) they are conducted on cold substrates or heated ones below $500^{\circ} \mathrm{C}$. The following four types of PVD are the most common in industrial environments:

\section{Magnetron sputtering;}

2. Cathode-arc evaporation under low pressure;

3. Electron beam evaporation from low-voltage source;

4. Triode-evaporating by means of electron gun with high-voltage cathode.

Coatings deposited by PVD methods are usually formed by beams of atoms and/or ions. For evaporation or sublimation of the particles, electron beam or arc discharge is used, while for magnetron sputtering usually $\mathrm{Ar}^{+}$ions accelerated in the electric field are employed. The above techniques are reactive in nature and atoms are moved into a vapor state through sublimation, metal evaporating from the surface of the molten pool, or by sputtering the solid magnetron target [21]. Tetrahedral amorphous carbon (ta-C) DLC coatings deposited by means of PVD method are synthesized from solid graphite targets. During the deposition process, carbon ionization takes place at low temperatures $\left(<100^{\circ} \mathrm{C}\right)$ and does not require the addition of hydrogen which would reduce the hardness of the layer.

Table 2 shows a comparison of mechanical properties and an indication of industrial use of DLC coatings deposited using PECVD and PVD methods. Figure 3 shows an industrial PVD/PECVD coating system unit allowing to obtain a repeatable coating compositions through an automatic deposition process following selected coating recipe.

\section{DLC COATING FUNCTIONALITY}

A wide range of available amorphous carbon DLC coating architectures and a number of possible deposition methods allow tailoring of the coating functionality to certain applications. The desirable properties of DLC coatings include high hardness, low friction, electrical insulation, anti-

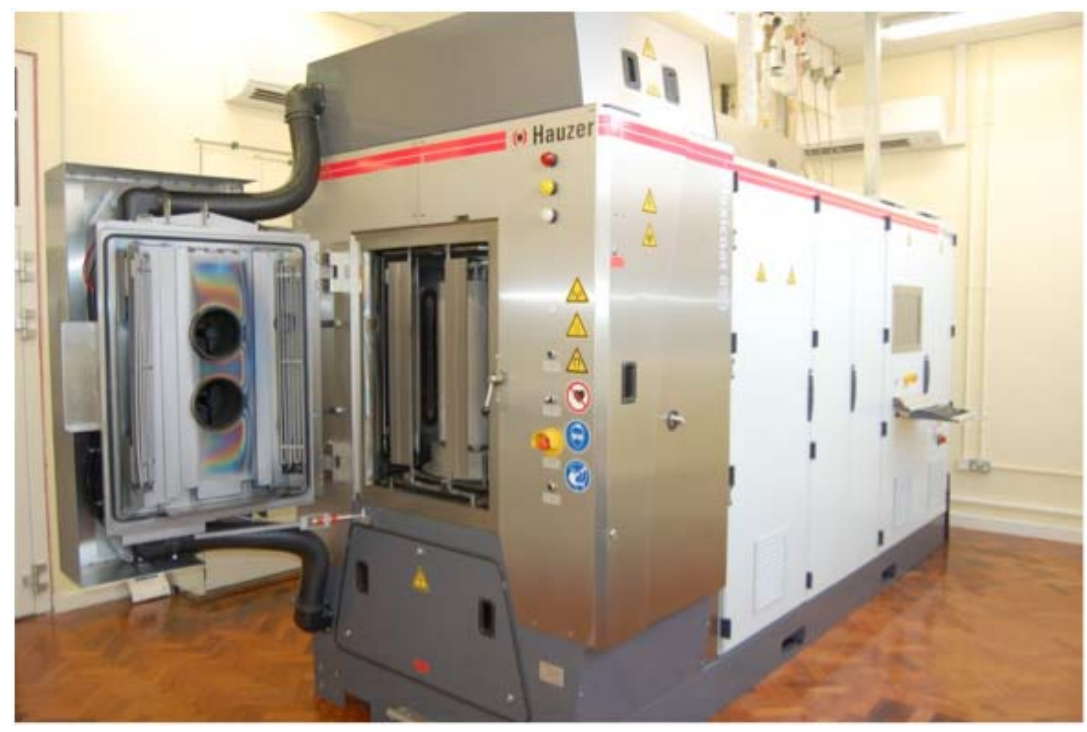

Figure 3: An industrial PVD/PECVD coting system unit. 
corrosion, chemical inertness, optical transparency, biological compatibility, ability to absorb photons selectively, smoothness and resistance to wear. From the perspective of oil and gas applications, the following three qualities are of the greatest relevance:

1. Improved tribological properties;

2. Reduced corrosion;

3. Anti-fouling properties.

\section{Tribology}

Tribology is defined as the science and technology of interacting surfaces in relative motion and it combines topics of lubrication, friction, wear and surface engineering into a complex framework for solving engineering problems. Surface engineering plays a central role in this process with functional coatings reducing friction and extending the lifetime of mechanical components. Tribology has an important economic impact, which strongly justifies its intensive exploration. In the 1966 Jost Report, the first-of-its-kind study which generated significant worldwide impact, it was estimated that up to $4 \%$ of UK GDP can be saved by overcoming friction related phenomena [23]. There are now numerous national and international societies, such as the Society for Tribologists and Lubrication Engineers (STLE) in the USA, whose members devote their effort and energy to advancing the field of tribology. Tribology principles in the oil and gas sector contribute to asset integrity management systems by providing solutions allowing engineering components to perform their required function effectively and efficiently whilst protecting health, safety and the environment. Protection against abrasive wear and reduction of friction are the two main areas where tribology positively affects the performance of engineering components in that sector.

Abrasive wear causes loss of material in the contact area due to the ploughing effect of the softer material by the particles of the harder material. Wear debris can be also generated and freely move within the contact area or be immobilized in one or both of the interacting surfaces further contributing to the interface damage. Depending on the type of surface damage, the following abrasive wear mechanisms are distinguished:

\section{Grooving; \\ 2. Micro-fatigue; \\ 3. Micro-cutting; \\ 4. Micro-cracking.}

The classical abrasive ploughing takes place when hardness of abrasive material is higher than the hardness of worn material. However, with significant differences between hardness of mated elements, the harder material can be subjected to wear. This is due to a great amount of hard debris pushed into the surface of the softer material which forms a sort of abrasive brush.

DLC coatings provide low friction and superior wear resistance. In gasoline engines, application of DLC coating reduced friction by $25 \%$ resulting in an overall $4 \%$ improvement of fuel efficiency [24]. The role of abrasive particle size on the wear of DLC coatings was investigated in [25]. The abrasive particle size was varied under the mixed lubrication regime and no delamination or any major damage to the coating was observed in the case of lubricating fluid having no sand. However, three-body abrasive wear leading to internal cracking, spallation and sequential removal of coating was observed with sand added in the lubricating fluid as an abrasive medium. The three-body wear mechanism was attributed to the entrainment of abrasive particles into the tribological contact. The influence of DLC coatings' mechanical properties on erosion resistance was studied in [26]. Abrasive resistance of the investigated coatings was found to depend mainly on the coating hardness, with the hardest DLC coating showing the least abrasive degradation. However, further cyclic loading testing showed that the hardest coating showed the most severe fatigue damage of all DLC coatings investigated.

\section{Corrosion}

Amorphous carbon DLC coatings are corrosion resistant and biocompatible with good cytological properties, which proved their successful application in the bio-medical sector [27]. In engineering applications, DLC coatings are applied to provide corrosion protection to metallic components. Corrosion performance of DLC coatings and role of interlayers on 316 steel were studied in [28]. It has been found that a-SiNx interlayer provided the best adhesion and significantly improved the corrosion resistance of the DLC. A two-order of magnitude improvement in the corrosion current density was recorded for that interlayer comparing to the DLC with the nitrided interlayer. Also, as a result of the formation of a passive silicon oxide film at the electrode/electrolyte interface, Si-doped DLC coatings exhibited improved corrosion barrier properties. Corrosion protection of DLC coatings doped with silicon deposited on magnesium alloy was studied in [29]. Incorporation of silicon in the DLC coating improved its corrosion protection and the corrosion performance improved with increasing silicon content in the coating. Further surface analysis carried out in this study indicated a presence of a thick oxide layer on the Si-DLC coating surfaces. It was observed that insulating properties of this oxide layer results in high anti-corrosion properties of the Si-DLC films. It was concluded that very low internal stress in the Si-DLC coatings is one of the reasons for the high anticorrosion performance of this system.

\section{Anti-Fouling}

Process-side fouling occurs across major oil and gas operations leading to increased maintenance costs and 
equipment failures. It has been observed that fouling has increased recently due to tougher regulations regarding process water use and as refineries use more difficult-toprocess, heavier crude oils in addition to the increase in processing of shale oil. Currently, scale formation is recognized as one of the major flow assurance problems affecting production in the oil and gas sector. Amongst many approaches to remove and prevent scaling, including chemical inhibition, chemical scale removers and mechanical methods, surface engineering has a potential to provide a new efficient way to control impact of scaling in oil and gas sector [30]. It is an established method in the control of biofouling but only a few attempts have been made to use it for the purpose of scale inhibition. In many industrial systems, scale formation causes significant problems, not when it precipitates in bulk solution but when it deposits on the surface. Surface deposition and precipitation are interlinked; however they have very different kinetics and the controlling bulk precipitation does not by default control surface scaling $[31,32]$.

\section{DLC COATING APPLICATIONS IN OIL AND GAS SECTOR}

\section{Protection Against Erosion-Corrosion}

Erosion-corrosion involves solid particle movement in a fluid stream (gaseous or liquid) causing material removal due to mechanical (wear) and chemical (corrosion) damage mechanisms. Amorphous carbon DLC coatings with their superior friction and wear properties combined with high hardness and good corrosion properties should be a suitable candidate for protection against erosion-corrosion. Indeed, they are recognized as a potential solution; however their limited thickness and brittleness due to high internal stresses limits their widespread application. Hence, DLC coatings for erosion-corrosion applications should be considered within a broader framework of a surface design process.

Surface coating design against erosion-corrosion includes adequate surface toughness, elasticity and coating adhesion. A sufficiently elastic surface will deflect and absorb impact energy during erosion, while flexible coating/substrate interface with high cohesion strength will eliminate coating delamination from the substrate (Figure 4). The ability of a material to resist fracture toughness (i.e., resistance to crack propagation) has been vital to the studies of erosion mechanics. Leyland et al. reported that coated system design should include consideration of $\mathrm{H} / \mathrm{E}$ ratio as fracture toughness would appear to be improved by high hardness and low elastic modulus [33]. High H/E indicates a surface's ability to absorb energy and recover elastically; hence, coating with high $\mathrm{H} / \mathrm{E}$ and a long elastic strain to failure will be able to accommodate large substrate deformations under load without yielding.

An additional factor which needs to be taken into consideration while designing surface for erosion-corrosion applications is erosive particle impact angle. Figure $\mathbf{5}$ shows erosive wear rates for brittle and ductile materials as a function of particle impact angle. It can be observed that ductile materials experience high erosion rates around $20^{\circ}$ to $30^{\circ}$ impact angle, while brittle materials do so at $90^{\circ}$. From the surface design perspective, this means that at normal impact angles coating should be sufficiently elastic to avoid high-stress peaks, while at inclined impact angles coating it should be hard enough to avoid grooving.

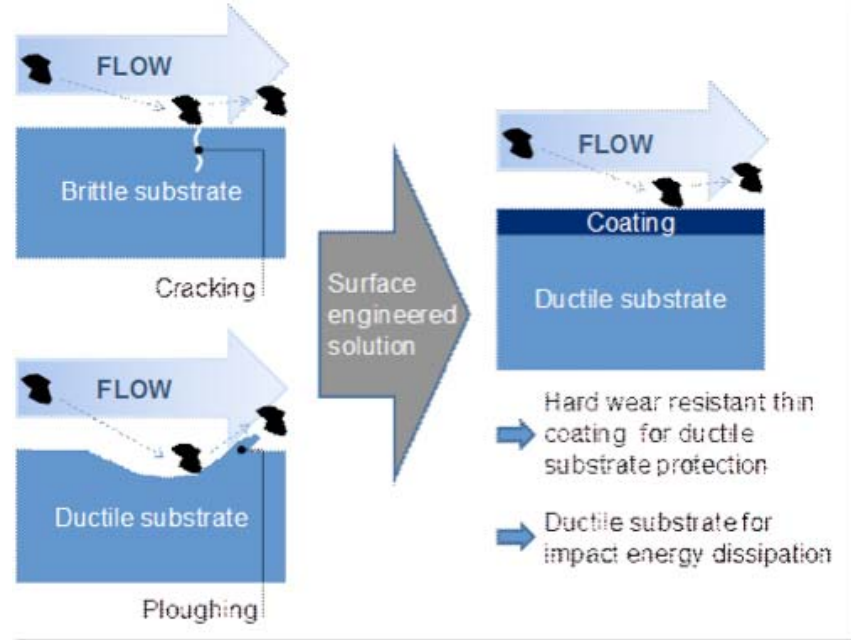

Figure 4: Surface coating design against erosion-corrosion.

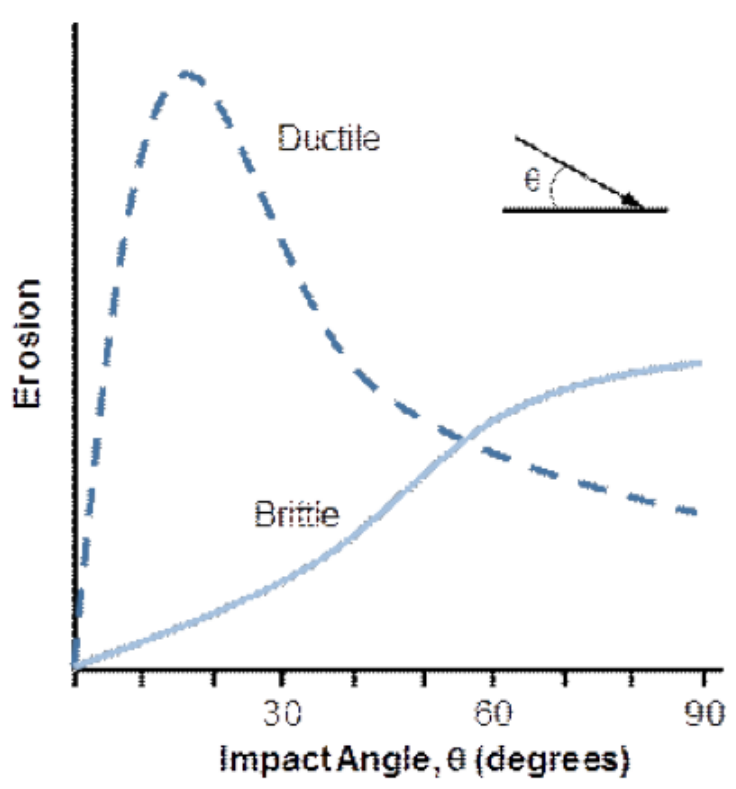

Figure 5: Erosive wear rates for brittle and ductile materials [after 34].

Adequate surface coating design against erosion-corrosion, typically involves a support coating between the DLC layer and the substrate. Jellesen et al. looked at erosion-corrosion of DLC coated low temperature gas-nitrided austenitic stainless steel [35]. It was observed that the combination of DLC and low temperature nitriding dramatically reduces the amount of erosion-corrosion of stainless steel under 
impingement of particles in a corrosive medium. DepnerMiller et al. investigated a hybrid coating architecture, where the DLC layer was deposited on top of top of a multilayer PVD coating system [36]. Residual compressive stresses and hardness of the coating system were measured and the abrasive degradation of the investigated coatings was found to depend mainly on coating hardness under combination of abrasive and fatigue loading with the hardest DLC coating showing least abrasive degradation. In contrast, the same coating showed the most severe fatigue damage when tested under cyclic loading. A sandwich structure with a polymeric amorphous DLC layer was proposed by S. Neuville as a novel approach for erosion-resistant coatings [37]. The composite architecture of the coating, composed of a soft polymeric amorphous carbon, an adhesion layer and a hard elastic anti-wear PECVD layer, showed promising results and its performance was theoretically analyzed.

\section{Protection of Internal Bores}

The major drawback of the PVD technology for industrial application is its limitation to line-of-sight deposition, which makes it impossible to produce a consistent coating on the internal surface of cylindrical substrates. This is less inconvenient in the case of PECVD technologies which rely on chemical reactions during deposition process. Nevertheless, the standard PECVD equipment is not specifically designed to handle efficiently coating deposition on the internal surface of cylindrical substrates. This has been addressed recently by development of a dedicated deposition method using a hollow cathode plasma immersion ion processing method for the deposition of silicon containing DLC coatings [38-40]. In this method, the plasma is

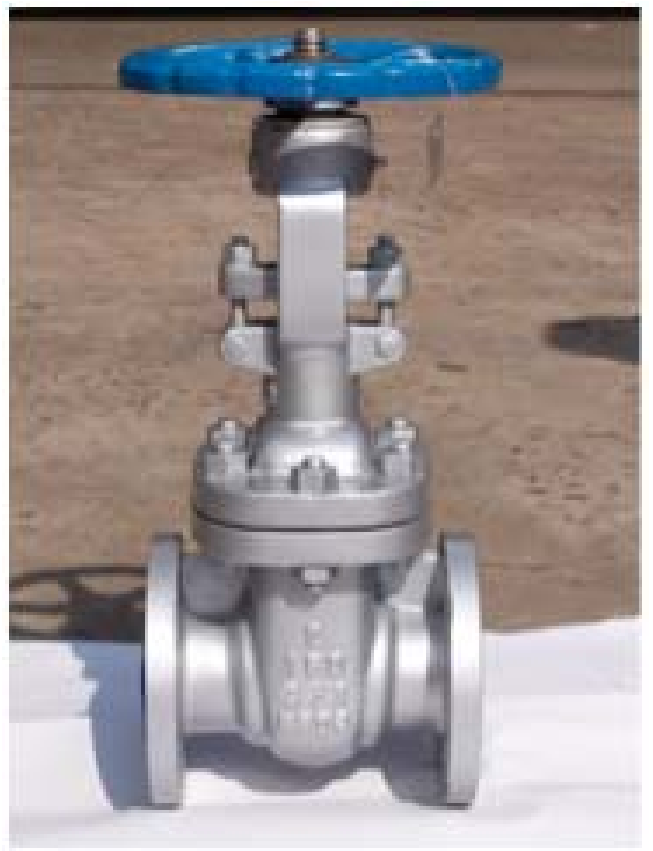

generated within the pipe itself and a gaseous precursor is introduced and ionized causing a coating to be deposited on the internal wall of the pipe. As a result, a multilayer Si-DLC coating with a film thickness up to 50 microns was generated and internal bores and enclosures up to three meters and an aspect ratio of 1:40 (length: diameter) have been coated. It has been reported that the coating has superior corrosion, fouling, wear and abrasion properties and apart from pipes, pump barrels, downhole pipes, drilling fixtures and drilling bores have been listed as potential applications in oil and gas industry.

\section{Protection of Flow Control Devices}

DLC coatings, due to their low friction and superior wear properties, proved to be an efficient solution for a variety of flow control devices including heart valves components [41] and internal combustion engine fuel injection valves [42]. The same properties make them suitable for flow control devices in oil and gas applications which are subjected to build-up of frictional forces in very aggressive chemical conditions, including exposure to hydrogen sulfide. Application of DLC coatings is especially cost effective on high value flow control devices, which are crucial for the operation and safety of the equipment and personnel. These include shut-off and knife gates as well as choke, check, stop, control, balancing, diaphragm, n-way, pneumatically actuated and butterfly valves (Figure 6).

In a flow-erosion-corrosion environment, operating conditions can vary from a corrosion dominated regime where there is no significant influence of the flow, to a completely erosion or abrasion dominated damage, which is completely caused by mechanical effects. Depending on the deposition method

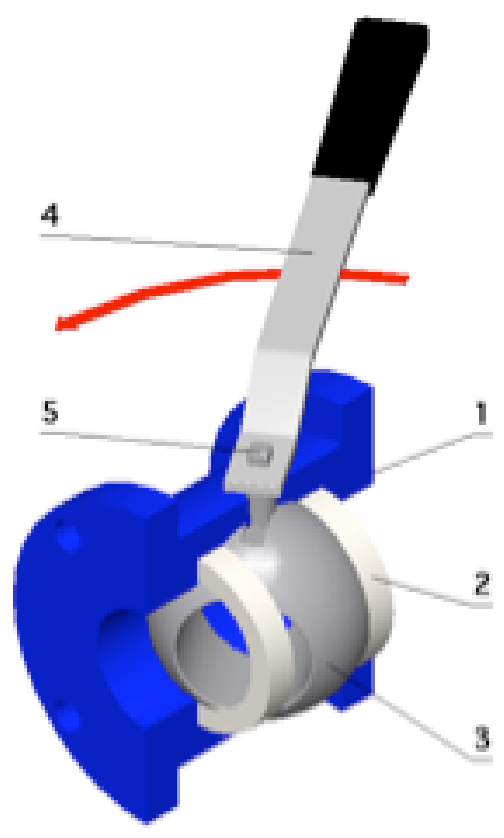

Figure 6: Valves, as a high value strategic components within the flow control systems are especially suited for application of DLC coatings; a) gate valve [43]; b) ball valve, 1 - body, 2 - seat, 3 - ball, 4- lever, 5 - stem [44]. 
used and chemical composition, DLC coating properties can be tailored to address durability challenges of flow control devices by providing:

1. Corrosion protection and chemical resistance to harsh media;

2. Superior mechanical properties against abrasive and adhesive wear (toughness and hardness);

3. Low coefficient of friction to increase trouble-free function and increase precision (elimination of adhesion cold welding and galling);

4. Anti-fouling properties preventing biological growth.

Hence, the operating conditions need to be fully understood in order to develop design guidelines for surface engineering systems to be used to enhance the durability of valves in conditions where corrosion, abrasion and erosion can reduce the life of the component.

\section{Protection Against Fouling}

The following three factors have been identified as key parameters for surface design strategy against scale formation:

1. Surface parameters, including natural surface roughness, but also imposed micro and nanostructuring to change the surface energy (wettability) [45];

2. Kinetics of surface scale deposition and the relationship between the time constant for bulk and surface deposition [46];

3. Induction time and saturation as pre-scaled surfaces show much higher growth rates than clean surfaces [47].

There is not much information available in the public domain on the impact of DLC type of coatings on fouling, however in the recent paper published by a group from Leeds University, it has been shown that DLC offer excellent potential for controlling calcium carbonate formation and has a profound effect on the initial stages of scale formation [48]. This work provided evidence that the surface is acting as a nucleation site for crystals to heterogeneously initiate and grow, and this process can be controlled by surface coatings.

\section{OPPORTUNITIES AND FUTURE CHALLENGES}

Corrosion and wear resistance are the main requirements for materials in the oil and gas sectors. Surface engineering can satisfy these requirements and there are a number of opportunities for DLC coatings to provide innovative and advanced solutions in that area:

1. DLC coatings' penetration of the oil and gas sectors is still very low and there is a significant opportunity to tap into existing know-how and expertise from other industry sectors where DLC coatings are well established, e.g., the automotive industry;

2. Increased functionality of existing components and systems can be achieved by application of DLC coatings, maximizing their reliability;

3. With their superior corrosion and mechanical properties, DLC coatings can provide increased efficiency and energy savings;

4. Increased safety can be achieved by application of more reliable surface technologies;

5. PECVD is a constantly developing field with novel emerging applications and technologies (e.g., low temperature deposition DLC films on polymers).

Future challenges include:

1. Achieving deposition process repeatability leading to perfect coating reproducibility (consistent quality);

2. Achieving more stable and less sensitive processes (wider process windows);

3. Developing technologies and methods for large scale/large area DLC deposition;

4. Bringing down capital investment costs and optimizing the operational cost models;

5. Developing further science behind DLC coatings deposition and application for improved understanding of their functionality.

\section{CONCLUSIONS}

Types of DLC coatings, their deposition methods and current applications in the oil and gas sectors have been reviewed in this paper. DLC coatings are unique in the sense that they are a diverse group of amorphous carbon films with a wide range of engineering properties. This allows the tailoring of DLC coating properties for specific applications by choosing suitable deposition method and adjusting their architectures. Three qualities of DLC coatings with the greatest relevance for oil and gas applications have been identified; these include: (i) improved tribological properties; (ii) reduced corrosion; and (iii) anti-fouling properties. Successful applications of DLC coatings in petroleum production have been reviewed, giving examples of protection against erosion-corrosion and fouling in flow control devices and in components where protection of internal surfaces in cylindrical structures is required. It has been highlighted that the application of DLC coatings in the oil and gas sectors is still very low, compared to other sectors; therefore, it is expected that demand for this type functional coatings has potential for steady growth. 


\section{Journal of Coating Science and Technology, 2014, Volume 1, No. 1}

\section{REFERENCES}

[1] Bell T. Surface Engineering: Past, Present, and Future. Surface Engineering 1990; 6(1): 31-40(10).

[2] Clarke A, Partridge A. A strategic review of the surface engineering industry in the UK, NAMTEC 2006.

[3] Heimann RB. Plasma-Spray Coating, VCH Publishers 1996.

[4] Javaherdashti R, Nwaoha C, Tan H, Eds. Corrosion and Material in the Oil and Gas Industries, CRC Press 2013. http://dx.doi.org/10.1201/b14703

[5] Singh R. Hot-Dip Galvanizing vs. Zinc Electroplating. Pipeline and Gas Journal 2013; 240(3).

[6] Sucháneka J, Smrkovskýa J, Blaškovičb $P$, Grinbergc NA. Erosive and hydroabrasive resistance of hardfacing materials. Wear 1999; 233-235: 229-236. http://dx.doi.org/10.1016/S0043-1648(99)00221-5

[7] Mattox DM. Handbook of Physical Vapor Deposition (PVD) Processing, Published by William Andrew 2010.

[8] Geiser J. Models and Simulation of Deposition Processes with CVD Apparatus: Theory and Applications, Nova Science Publishers 2009.

[9] Quinto DT. Technology perspective on CVD and PVD coated metalcutting tools. International Journal of Refractory Metals and Hard Materials 1996; 14: 7-20.

http://dx.doi.org/10.1016/0263-4368(96)83413-5

[10] Aisenberg S, Chabot R. Ion beam deposition of thin films of diamondlike carbon. Journal of Applied Physics 1971; 42: 2953-2958. http://dx.doi.org/10.1063/1.1660654

[11] Robertson J. Diamond-like amorphous carbon. Materials Science and Engineering 2002; R37: 129-281.

[12] Robertson J. Deposition and properties of diamond-like carbon. Material Research Society Symposium Proceedings 1999; 555: 12.

[13] Robertson J. Mechanical properties and structure of diamond-like carbon. Diamond and Related Materials 1992; 1: 397-406. http://dx.doi.org/10.1016/0925-9635(92)90137-D

[14] Grill A. Diamond-like carbon: state of the art. Diamond and Related Materials 1999; 8: 428-434. http://dx.doi.org/10.1016/S0925-9635(98)00262-3

[15] Grishke M, Hieke A, Morgenweck F, Dimigen H. Variation of the wettability of DLC-coatings by network modification using silicon and oxygen. Diamond Related Materials 1998; 7: 454-458. http://dx.doi.org/10.1016/S0925-9635(97)00237-9

[16] Donnet C, Fontaine J, Grill A, Patel V, Jahnes C, Belin M. Wearresistant fluorinated diamondlike carbon films. Surface and Coatings Technology 1997; 94-95: 531-536. http://dx.doi.org/10.1016/S0257-8972(97)00462-3

[17] Grill A, Patel V, Jahnes C. Novel Low k Dielectrics Based on Diamondlike Carbon Materials. Journal of The Electrochemical Society 1998; 145: 1649-1653. http://dx.doi.org/10.1149/1.1838531

[18] Arkel van AE, Boer de JH, Zs. Anorg. Chemie 1925; 148: 345.

[19] Bunshah RF. Deposition Technologies for Films and Coatings, New Jersey, Noyes Publications 1982.

[20] Mattox DM. Handbook of Physical Vapor Deposition (PVD) Processing, William Andrew 2010.

[21] Münz WD, Surface and Coatings Technology 1991; 48: 81. http://dx.doi.org/10.1016/0257-8972(91)90130-O

[22] IHI Hauzer Techno Coating B.V., DLC Coating: http://www.hauzertechnocoating.com/en/plasma-coatingexplained/dlc-coating/ (Oct. 22, 2013).

[23] Jost P. (Chairman), Lubrication (Tribology) Education and Research A report on the present position and industry needs, Her Majesty's Stationery Office, London 1966.

[24] Maruyama $\mathrm{H}$. The Potential of the CDM and CO2 Reduction from Road Transportation, Inst. for Transport Policy Studies, Japan 2007.

[25] Haque T, Ertas D, Ozekcin A, Jin HW, Srinivasan R. The role of abrasive particle size on the wear of diamond-like carbon coatings. Wear 2013; 302: 882-889.

http://dx.doi.org/10.1016/i.wear.2013.01.080

[26] Depner-Miller U, Ellermeier J, Scheerer H, Oechsner M, Bobzin K, Bagcivan N, Brögelmann T, Weiss R, Durst K, Schmid C. Influence of application technology on the erosion resistance of DLC coatings. Surface and Coatings Technology. In Press.
Mirza EH, Ali SFA, Asif M, Azhar bin Ibrahim WM, Najam ul Hassan, $S$. Evaluation of anti-corrosion properties of DLC coatings for medical devices, IEEE CONFERENCE PUBLICATIONS. International Conference on Biomedical Engineering (ICoBE), Penang 2012; pp. 117-122.

[28] Azzi M, Amirault P, Paquette M, Klemberg-Sapieha JE, Martinu L. Corrosion performance and mechanical stability of $316 \mathrm{~L} / \mathrm{DLC}$ coating system: Role of interlayers. Surface and Coatings Technology 2010; 24: 3986-3994.

http://dx.doi.org/10.1016/i.surfcoat.2010.05.004

[29] Choi J, Nakao S, Kim J, Ikeyama M, Kato T. Corrosion protection of DLC coatings on magnesium alloy. Diamond and Related Materials 2007; 16: 1361-1364.

http://dx.doi.org/10.1016/i.diamond.2006.11.088

[30] Wang Z, Neville A, Meredith A. How and why does scale stick - Can the surface be engineered to decrease scale formation and adhesion? SPE 94993, Proceedings of the 7th International Symposium on Oilfield Scale held in Aberdeen, UK, 11-12 May 2005 http://dx.doi.org/10.2118/94993-MS

[31] Chen T, Neville A, Yuan M. Assessing the effect of Mg2+ on $\mathrm{CaCO} 3$ scale formation - bulk precipitation and surface deposition. Journal of Crystal Growth 2005; 275/1-2: 1347-1353 http://dx.doi.org/10.1016/i.jcrysgro.2004.11.169

[32] Chen T, Neville A, Yuan M. Influence of Mg2+ on $\mathrm{CaCO} 3$ formation bulk precipitation and surface deposition. Chemical Engineering Science 2006; 61: 5318-5327.

http://dx.doi.org/10.1016/j.ces.2006.04.007

[33] Leyland A, Matthews A. On the significance of the $\mathrm{H} / \mathrm{E}$ ratio in wear control: a nanocomposite coating approach to optimised tribological behaviour. Wear 2000; 246(1-2): 1-11.

[34] Hutchings IM. Tribology: Friction and Wear of Engineering Materials, London, Edward Arnold 1992

[35] Jellesen MS, Christiansen TL, Rischel Hilbert L, Møller P. Erosioncorrosion and corrosion properties of DLC coated low temperature gas-nitrided austenitic stainless steel. Wear 2009; 267: 1709-1714. http://dx.doi.org/10.1016/i.wear.2009.06.038

[36] Depner-Miller U, Ellermeier J, Scheerer H, Oechsner M, Bobzin K, Bagcivan N, Brögelmann T, Weiss R, Durst K, Schmid C. Influence of application technology on the erosion resistance of DLC coatings. Surface and Coatings Technology, In Press.

http://dx.doi.org/10.1016/i.surfcoat.2013.07.043

[37] Neuville S. An approach for erosion-resistant coatings by the use of sandwich a-C:H/ta-CNx. Surface and Coatings Technology 1998 106: $277-281$ http://dx.doi.org/10.1016/S0257-8972(98)00575-1

[38] Lusk D, Gore M, Boardman W, Casserly T, Boinapally K, Oppus M Upadhyaya D, Tudhope A, Gupta M, Cao Y, Lapp S. Thick DLC films deposited by PECVD on the internal surface of cylindrical substrates. Diamond and Related Materials 2008; 17: 1613-1621. http://dx.doi.org/10.1016/i.diamond.2008.01.051

[39] Boardman W, Boinapally K, Casserly T, Gupta M, Dornfest C Upadhyaya D, Cao Y, Oppus M. Corrosion and Mechanical Properties of Diamond-like Carbon Films Deposited Inside Carbon Steel Pipes. NACE Corrosion 2008; Paper 08032, 1-11.

[40] Gore M, Boardman W. Emergence of Diamond-like Carbon Technology: One Step Closer to OCTG Corrosion Prevention. SPE International Conference on Oilfield Corrosion 2010; Paper 131120: 1-9.

\section{http://dx.doi.org/10.2118/131120-MS}

[41] Hauert R. A review of modified DLC coatings for biological applications. Diamond and Related Materials 2003; 12: 583-589. http://dx.doi.org/10.1016/S0925-9635(03)00081-5

[42] Treutler ChPO. Industrial use of plasma-deposited coatings for components of automotive fuel injection systems. Surface and Coatings Technology 2005; 200: 1969-1975.

\section{http://dx.doi.org/10.1016/i.surfcoat.2005.08.012}

[43] Source: http://en.wikipedia.org/wiki/File:Valve.jpg; author: HS. This file is licensed under the Creative Commons Attribution 3.0 Unported license.

[44] Source: http://en.wikipedia.org/wiki/File:Ball.PNG; author: Ruben Castelnuovo. This file is licensed under the Creative Commons Attribution-Share Alike 3.0 Unported license.

[45] Cheong W, Neville A, Gaskell PH, Abbott S. Using Nature to Provide Solutions to Calcareous Scale Deposition, Proceedings of SPE International Oilfield Scale Conference held in Aberdeen, UK, 28-29 May 2008, SPE 114082.

http://dx.doi.org/10.2118/114082-MS 
Journal of Coating Science and Technology, 2014, Volume 1, No. 1

[46] Setta F-A, Neville A. Efficiency assessment of inhibitors on $\mathrm{CaCO} 3$ precipitation kinetics in the bulk and deposition on a stainless steel surface (316 L). Desalination 2011; 281: 340-347.

http://dx.doi.org/10.1016/i.desal.2011.08.021

[47] Ciolkowski M, Neville A, Hu X, Mavredaki E. Influence of brine with different supersaturation ratio on corrosion processes for pipeline material carbon steel $\mathrm{X} 65$, scale deposition and performance of combined inhibitor. Society of Petroleum Engineers - SPE
International Conference and Exhibition on Oilfield Corrosion 2012; pp. 254-263.

[48] Cheong WC, Gaskell PH, Neville A. Substrate effect on surface adhesion/crystallisation of calcium carbonate. Journal of Crysta Growth 2013; 363: 7-21.

http://dx.doi.org/10.1016/j.jcrysgro.2012.09.025 